Check for updates

Cite this: Mater. Adv., 2021, 2,6326

Received 13th July 2021 Accepted 10th August 2021

DOI: 10.1039/d1ma00604e

rsc.li/materials-advances

\title{
Phenanthroimidazole-based bipolar carbazoles featuring cyano substituents to realize efficient deep-blue electroluminescence with an external quantum efficiency of nearly $6 \% \dagger$
}

\author{
Anuj Sharma, ${ }^{a}$ K. R. Justin Thomas, (D)*a Mangey Ram Nagar ${ }^{\mathrm{b}}$ and \\ Jwo-Huei Jou (iD ${ }^{b}$
}

\begin{abstract}
Developing deep-blue bipolar materials with high quantum yields remains a crucial issue in organic light-emitting diodes. The excited-state characteristics of dyes play a pivotal role in controlling the photoluminescence (PL) and electroluminescence (EL) outcomes. Here, a series of carbazolephenanthroimidazole dyads with and without phenyl spacer units have been designed and synthesized. The functional properties are tunable by substitution of cyano units at various positions on the carbazole. The cyanofeatured dyes exhibit a bathochromic shift in their emission spectra that is attributable to the contribution of a charge-transfer component in the excited state, which is further confirmed by solvatochromism studies. Accordingly, the dyes showed larger Stokes shifts due to a significant reorganization of the molecular structure in the excited state. The enhanced CT component is expected to benefit the exciton utilization efficiency of singlet energy states, thereby offering better EL performances. All dyes showed excellent thermal stability upon cyanation of carbazole-phenanthroimidazole derivatives. Electrochemical studies revealed stabilization of the lowest unoccupied molecular orbitals (LUMOs) upon the addition of cyano units to the central carbazole and realized maximum stabilization for the dyes containing cyano units at the $\mathrm{C} 2$ and $\mathrm{C} 7$ positions. The dyes were utilized as dopant emitters in solution-processed OLED devices and exhibited pure blue emission with a $\mathrm{CIE}_{x, y}$ coordinate of $(0.16,0.06)$ and an external quantum efficiency of $5.7 \%$.
\end{abstract}

\section{Introduction}

Over the past three decades, significant advancements have been made in the development of efficient organic emitters for accessing highly performing organic light-emitting diodes. However, designing fluorescent organic small molecules with highly efficient deep-blue electroluminescence has remained a primary challenge for materials chemists. ${ }^{1}$ Developing new and advanced blue-emitting molecular systems increases the color gamut and decreases the power consumption in solid-state lighting sources. ${ }^{2}$ Notably, small organic fluorescent emitters are an attractive class of molecular systems with unique advantages such as a facile synthetic methodology, high purity, monodispersity, good solubility and easy purification techniques. ${ }^{3-5}$ All these qualities make them a potential candidate for electronic

\footnotetext{
${ }^{a}$ Organic Materials Laboratory, Department of Chemistry,

Indian Institute of Technology Roorkee, Roorkee-247667, India.

E-mail: krjt@cy.iitr.ac.in; Tel: +91-1332-285376

${ }^{b}$ Department of Material Science and Engineering, National Tsing Hua University, Hsinchu 30013, Taiwan

$\dagger$ Electronic supplementary information (ESI) available. See DOI: 10.1039/ d1ma00604e
}

devices such as organic light-emitting diodes, light-emitting electrochemical cells, etc. $^{6}$

Recently, phenanthroimidazole-based organic materials have gained significant attention in optoelectronic devices due to their excellent rigidity to offer high thermal stability, a facile synthesis for large-scale production, and efficient PLQY values for better exciton utilization. ${ }^{7-9}$ All of these properties make these molecules a superior class of bipolar materials and can provide blue-emitting OLED devices. ${ }^{10-12}$ It has been observed in the literature that substitution at the $\mathrm{C} 2$ position of phenanthroimidazole enhances the degree of $\pi$-conjugation in the molecular structure. ${ }^{13,14}$ Also, some unique phenomena have been observed in these phenanthroimidazole derivatives, such as the hybridized local and charge transfer (HLCT) state and thermally activated delayed fluorescence (TADF) to rapid upconversion of triplet excitons into singlet excited states. ${ }^{15,16}$ This excited state upconversion allows the enhancement of exciton utilization efficiency (EUE) that enables exciton relaxation through radiative pathways. However, the excited state based on HLCT characteristics offers co-existing LE (locally excited) and CT (charge transfer) excited states. ${ }^{17,18}$ The locally excited state component offers efficient radiative fluorescence decay due to a large 

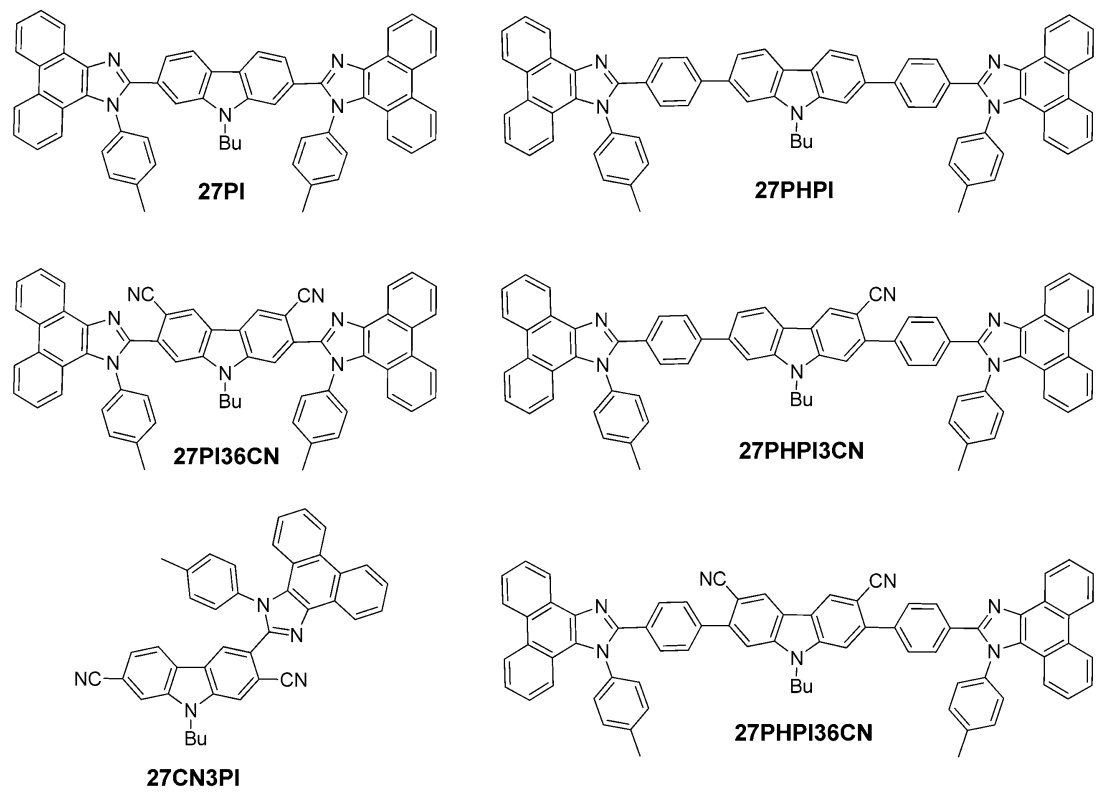

Chart 1 Structures of the synthesized dyes 27PI, 27PI36CN, 27PHPI, 27CN3PI, 27PHPI3CN and 27PHPI36CN

transition moment, while the charge-transfer excited state allows a small energy splitting between the singlet and triplet states for an efficient reverse intersystem crossing (RISC) process in higher-lying excited states. ${ }^{19,20}$ Thus, using HLCT materials as the emitter in OLED devices may provide a better EL performance. ${ }^{21}$ As observed in the literature, the incorporation of cyano groups in the molecular framework increases the charge-transfer (CT) characteristics in the excited state. ${ }^{22,23}$ The CT contribution, however, is expected to decrease the internal quantum efficiency. Still, at the same time, it increases the production of singlet excitons, and hence a high EL efficiency in the HLCT molecules can be expected. Therefore, it remains a challenge to access a balanced contribution of LE and CT emissive states. $^{24-26}$

So far, the substitution effect of cyano groups at the N1 position of phenanthroimidazole has been investigated in fluorescence- or phosphorescence-based OLED devices to explore the concept of HLCT or quasi-HLCT. ${ }^{27}$ However, varying the donoracceptor strength of substituents attached at the $\mathrm{C} 2$ position of phenanthroimidazole has rarely been investigated. Hence, understanding the structure-property fundamentals of the substitution effect becomes essential in designing efficient organic lightemitting devices. ${ }^{28-30}$ On the other hand, carbazole-based materials possessing a good hole-transporting nature, favorable triplet energies and multi-functionalized ability have been extensively investigated in the development of highly efficient OLED devices. ${ }^{31}$ Although the symmetrical bipolar properties of multifunctionalized carbazoles are well known in the literature, ${ }^{32}$ unsymmetrical derivatives that feature donor and acceptor units remain elusive. Moreover, the cyano group is also a promising electron-accepting unit for an improved EL performance. Recently, our group has reported the multi-substituted asymmetrical bipolar carbazole derivatives featuring triphenylamine as the donor and cyano as the acceptor to unravel the positiondependent hybrid local and charge-transfer energy states. ${ }^{33 a}$ There are only a few reports on carbazole- and phenanthroimidazolebased bipolar materials that are known with a D-A-type or D-A-Dtype architecture. For example, Peng et al. synthesized phenanthroimidazole-based derivatives bearing terminal carbazole linked by spacer groups, such as phenylvinyl, 1,4-phenylene, and phenylvinylcarbazolylvinyl, which exhibited bluish green electroluminescence. ${ }^{33 b}$ Butkute et al. reported multi-substituted phenanthroimidazole-based solid-state emissive bipolar materials containing carbazole and diphenylamino as donor groups and elaborated electroplex formation in host-guest systems. ${ }^{33 c}$ Recently, Sharma et al. designed cyano-decorated carbazolebased bipolar derivatives featuring phenanthroimidazole, and they investigated the beneficial role of appended cyano chromophores in balanced charge transport and efficient charge recombination in doped-OLED devices. ${ }^{33 d}$

In this article, we propose a donor-acceptor strategy to design cyano-incorporated carbazole-phenanthroimidazole derivatives (Chart 1) and compared their excited state with the non-cyano-substituted dyes. The substitution of a cyano chromophore at the $\mathrm{C} 2, \mathrm{C} 7, \mathrm{C} 3$ and $\mathrm{C} 6$ positions of carbazole reveals interesting absorption and emission properties depending upon the nature of the $\pi$-conjugation. Moreover, it also explains the role of the cyano chromophore in inducing the charge-transfer contribution in the molecular system. The hybrid system of carbazole substituted with cyano and phenanthroimidazole fragments helps to study the functional properties and investigate the structure-property relationship.

\section{Results and discussion}

\section{Synthesis and characterization}

A unique molecular design strategy was adopted to unravel the effect of cyano substitution at the $\mathrm{C} 3, \mathrm{C} 2, \mathrm{C} 7$ and/or C6 position 


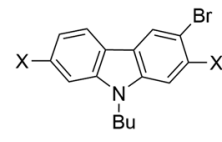

$X=R 1,5(95 \%)$

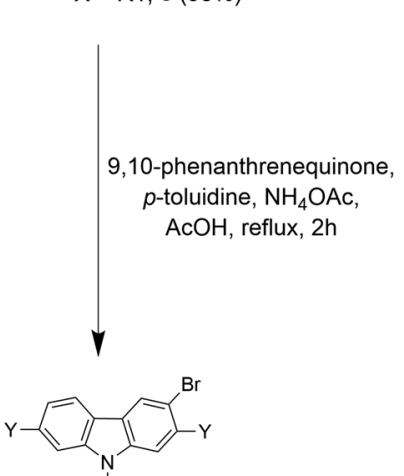

$\mathrm{B}$
$\mathrm{Bu}$

$\mathrm{Y}=\mathrm{R} 3, \mathbf{7}(59 \%)$
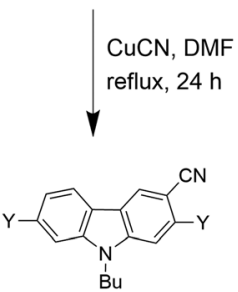

$\mathrm{Y}=\mathrm{R} 3$, 27PHPI3CN (65\%)
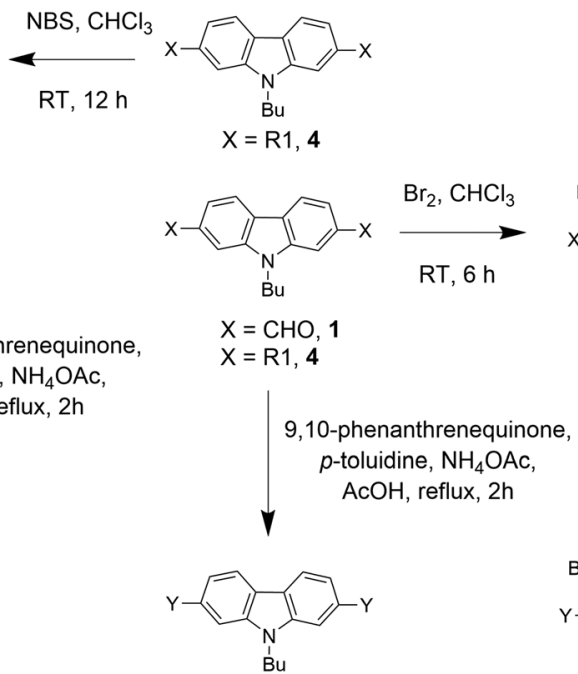

$Y=R 2,27 P I(44 \%)$

$\mathrm{Y}=\mathrm{R} 3,2 \mathrm{PHPI}(78 \%)$

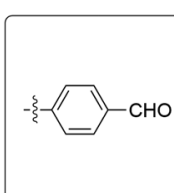

R1

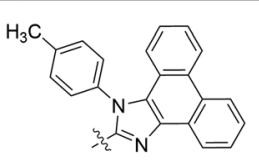

R2

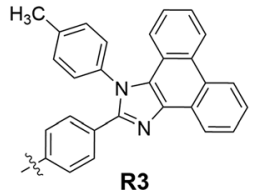

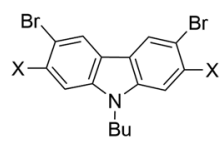

$\mathrm{X}=\mathrm{CHO}, 2(53 \%)$

$\mathrm{X}=\mathrm{R} 1, \mathbf{6}(77 \%)$

9,10-phenanthrenequinone,
p-toluidine, $\mathrm{NH}_{4} \mathrm{OAc}$,

$Y$

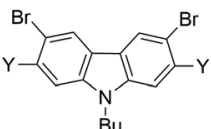

$Y=R 2,3(66 \%)$

$Y=R 3,8(65 \%)$

CuCN, DMF reflux, $24 \mathrm{~h}$<smiles>[Y]c1cc2c(cc1C#N)c1cc([Y])c(C#N)cc1n2[B]</smiles>

$\mathrm{Y}=\mathrm{R} 2,27 \mathrm{PI} 36 \mathrm{CN}(69 \%)$

$\mathrm{Y}=\mathrm{R} 3,27 \mathrm{PHPI} 36 \mathrm{CN}(70 \%)$

Scheme 1 Synthetic protocol of the dyes 27PI, 27PHPI, 27PI36CN, 27PHPI3CN and 27PHPI36CN.

of the phenanthroimidazole-decorated carbazole core. In the dyes, except for 27CN3PI, the $\mathrm{C} 2$ and $\mathrm{C} 7$ positions of the carbazole core were substituted with phenanthroimidazole chromophores enabled with or without a phenyl spacer. The synthetic protocol employed to access the target molecules is shown in Schemes 1 and 2. The key starting materials 9-butyl9H-carbazole-2,7-dicarbaldehyde (1), 4,4'-(9-butyl-9H-carbazole2,7-diyl)dibenzaldehyde (4) and 2,7-dibromo-9-butyl-9Hcarbazole (9) were synthesized by following the literature procedure. $^{34}$ The final dyes, 27PI and 27PHPI, were chiefly synthesized via a one-pot condensation reaction of 9,10phenanthrenequinone, $p$-toluidine and the respective carbazole dicarbaldehyde (1 and $\mathbf{4}$ ) under reflux conditions in the presence of $\mathrm{NH}_{4} \mathrm{OAc}$ and acetic acid for $2 \mathrm{~h}$. This simple strategy of making the phenanthroimidazole derivative was facile and allowed a wide scope for tuning the photophysical properties by using different aldehydes. ${ }^{35}$ The dibromo intermediates 2 and 6 were obtained using liquid bromine in chloroform, whereas compound $\mathbf{5}$ was synthesized via selective bromination using $\mathrm{N}$-bromosuccinimide. The formylation of compound 9 using the Vilsmeier-Haack reagent gave the monoformylated product 10. The phenanthroimidazole precursors $(3,7$, 8 and 11) were obtained using the same one-step condensation strategy. The synthesis of the target dyes (27PI36CN, 27PHPI3CN, 27PHPI36CN and 27CN3PI) from the aforementioned mono or dibromo derivatives $(3,7,8$ and 11) was accomplished via the

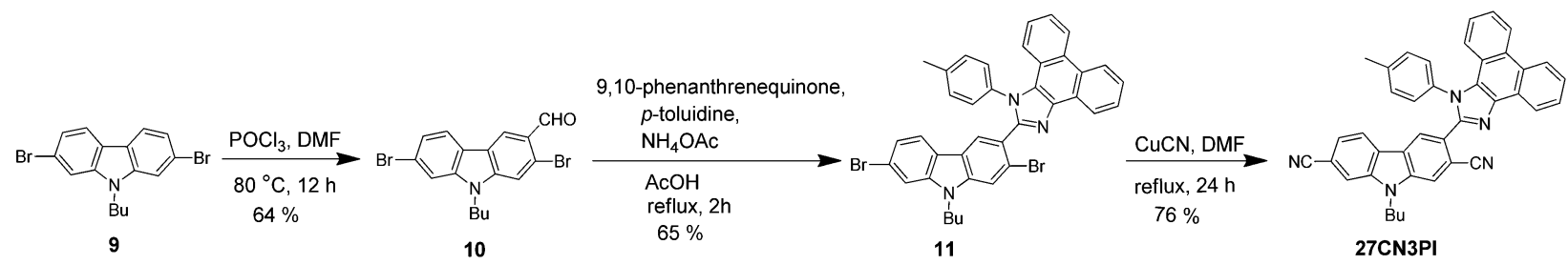

Scheme 2 Synthetic protocol of the dye 27CN3PI. 

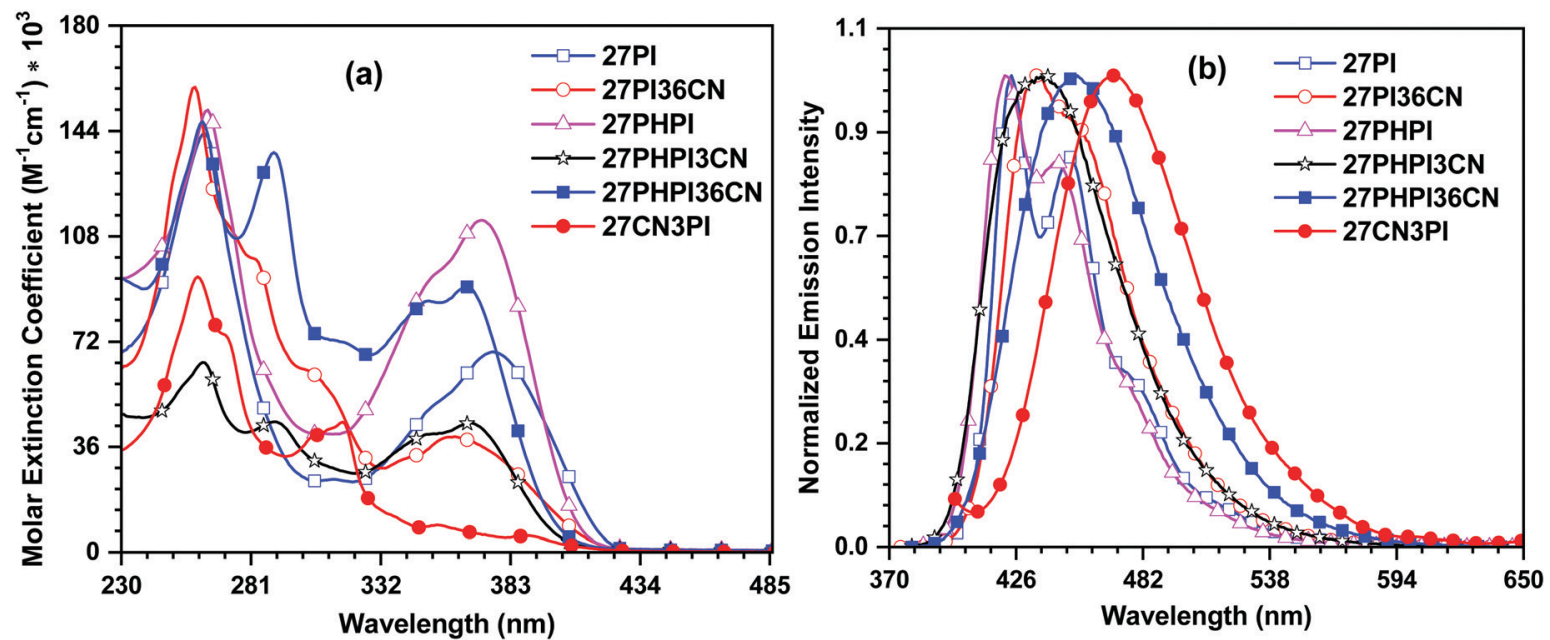

Fig. 1 (a) Absorption and (b) emission spectra of the dyes recorded in dichloromethane solution.

cyanation reaction using $\mathrm{CuCN}$ in DMF in good yield. Finally, all of the dyes were comprehensively characterized using proton $\left({ }^{1} \mathrm{H}\right)$ and carbon $\left({ }^{13} \mathrm{C}\right)$ nuclear magnetic resonance (NMR) spectroscopy and high-resolution mass spectroscopy (HRMS). The dyes exhibited good solubility in common organic solvents except for alcohol.

\section{Photophysical properties}

The UV-visible absorption characteristics of the dyes were investigated in dichloromethane solution $\left(1 \times 10^{-5} \mathrm{M}\right)$ (Fig. 1). The photophysical parameters are summarized in Table 1. The absorption profiles feature at least three prominent absorption bands with some weak shoulder peaks. The high-energy absorption bands at around $260 \mathrm{~nm}$ and $290 \mathrm{~nm}$ correspond to the phenyl group attached to the N1 position of phenanthroimidazole and the $n-\pi^{*}$ transition of the carbazole core, respectively. ${ }^{36,37}$ The longer wavelength absorption peaks between $308 \mathrm{~nm}$ and $389 \mathrm{~nm}$ are attributable to the delocalized $\pi-\pi^{*}$ transition between the cyano-substituted carbazole chromophores and the phenanthroimidazole unit. The parent molecules 27PI and 27PHPI exhibit similar absorption maxima; however, the latter compound shows a significant increment in the molar extinction coefficient. The incorporation of the phenyl spacer does not change the absorption significantly, which indicates poor electronic communication between the carbazole and the PI chromophores. This might occur due to the increased dihedral angle in 27PHPI $\left(\sim 37^{\circ}\right)$ in comparison with 27PI $\left(\sim 29^{\circ}\right)$, attributed to reduced $\pi$-conjugation in the former. The incorporation of the cyano chromophore at the C3 and/or C6 positions of these parent dyes results in the blue-shifted absorption maxima in 27PI36CN, 27PHPI3CN and 27PHPI36CN. This could be due to increased steric hindrance in the molecules leading to a larger dihedral angle between the carbazole and PI units and poor conjugation (see Fig. S4, ESI $\dagger$ ). It also reveals the role of the auxiliary chromophore on the absorption spectra of the dyes 27PI36CN, 27PHPI3CN and 27PHPI36CN. Importantly, the dye 27CN3PI showed a red-shifted band with a weaker absorption intensity. This might arise due to the weak intramolecular charge transfer from phenanthroimidazole to 2,7-dicyanocarbazole. The dye 27CN3PI also exhibits a small molar extinction coefficient between $330 \mathrm{~nm}$ and $390 \mathrm{~nm}$, which is attributed to the availability of one phenanthroimidazole unit for $\pi$-conjugation when compared with the two phenanthroimidazole groups in the other dyes. By comparing the absorption profile of the dye 27CN3PI with the known compound 2-(9-hexyl$9 H$-carbazol-3-yl)-1-phenyl-1 $H$-phenanthro[9,10- $d]$ imidazole $(\mathbf{H 1}){ }^{38}$

Table 1 Photophysical parameters of the dyes recorded in dichloromethane

\begin{tabular}{|c|c|c|c|c|c|c|c|c|c|}
\hline Dye & $\lambda_{\max }{ }^{a}\left(\mathrm{~nm}\left(\varepsilon_{\max }, \mathrm{M}^{-1} \mathrm{~cm}^{-1} \times 10^{3}\right)\right)$ & $\begin{array}{l}\lambda_{\mathrm{em}}\left(\mathrm{sol}^{b} / \mathrm{film}^{c}\right)(\mathrm{nm}) \\
\left(\Phi_{\mathrm{f}}(\mathrm{sol} / \mathrm{film})\right)^{d}\end{array}$ & $\begin{array}{l}\text { Stokes } \\
\text { shift }\left(\mathrm{cm}^{-1}\right)\end{array}$ & $\begin{array}{l}T_{\mathrm{d}}{ }^{e} / T_{\mathrm{g}} \\
\left({ }^{\circ} \mathrm{C}\right)\end{array}$ & $\begin{array}{l}E_{\text {ox }}^{f} \\
\text { (V) }\end{array}$ & $\begin{array}{l}\mathrm{HOMO}^{g} \\
(\mathrm{eV})\end{array}$ & $\begin{array}{l}\operatorname{LUMO}^{h} \\
(\mathrm{eV})\end{array}$ & $\begin{array}{l}E_{0-0}{ }^{i} \\
(\mathrm{eV})\end{array}$ & $\tau^{j}(\mathrm{~ns})$ \\
\hline 27PI & 376 (68.50), 313 (sh), 263 (143.05) & $424,449 / 479(0.81 / 0.51)$ & 3011 & $486 / 150$ & 0.58 & -5.38 & -2.34 & 3.04 & 1.87 \\
\hline 27PHPI3CN & 368 (44.11), 350 (sh), 291 (44.58), 262 (64.93) & $436 / 474(0.85 / 0.59)$ & 4238 & $548 / 154$ & 1.10 & -5.90 & -2.75 & 3.15 & - \\
\hline 27PHPI36CN & 366 (90.62), 351 (sh), 290 (136.66), 262 (147.24) & $452 / 471(0.84 / 0.62)$ & 5199 & $555 / 155$ & 1.13 & -5.93 & -2.85 & 3.08 & 1.26 \\
\hline 27CN3PI & 389 (5.67), 355 (9.19), 317 (44.47), 260 (94.12) & $470 / 459(0.58 / 0.34)$ & 4430 & $435 / 152$ & 1.08 & -5.88 & -2.91 & 2.97 & 1.38 \\
\hline
\end{tabular}

${ }^{a}$ Absorption spectra recorded in dichloromethane $\left(1 \times 10^{-5} \mathrm{M}\right) .{ }^{b}$ Emission spectra recorded in dichloromethane $\left(1 \times 10^{-6} \mathrm{M}\right) \cdot{ }^{c} \mathrm{Measured}$ for drop-cast thin films. ${ }^{d}$ Absolute quantum yields measured using the calibrated integrated sphere method. ${ }^{e}$ Temperature corresponding to $10 \%$ weight loss. ${ }^{f}$ Measured for $0.1 \mathrm{mM}$ dichloromethane solution and the potentials are quoted with reference to the ferrocene internal standard. ${ }^{g} \mathrm{HOMO}=-\left(4.8+E_{\mathrm{Ox}}\right) \cdot{ }^{h}$ LUMO $=\mathrm{HOMO}+E_{0-0} \cdot{ }^{i}$ Optical band gaps obtained from the intersection of the absorption and emission spectra. ${ }^{j} \mathrm{PL}$ decay lifetimes recorded in toluene solution. 

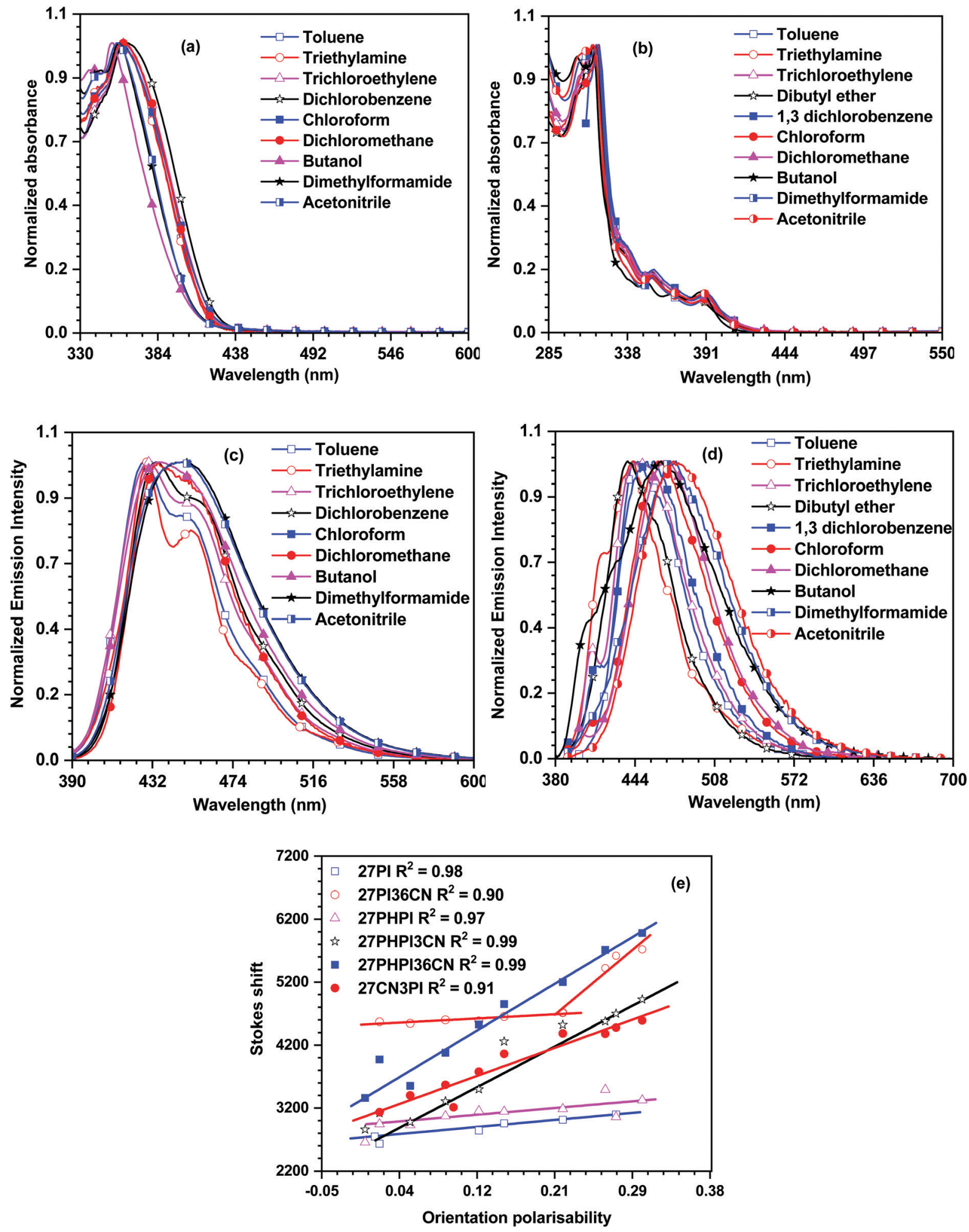

Fig. 2 Absorption and emission spectra of the dyes $27 \mathrm{PI} 36 \mathrm{CN}$ ( $\mathrm{a}$ and $\mathrm{c}$ ) and $27 \mathrm{CN} 3 \mathrm{PI}$ ( $\mathrm{b}$ and d) recorded in different polarity solvents, and the LippertMataga plots for the dyes (e).

an additional red-shifted weakly intense band is seen in the former dye that probably originates from the enhanced intramolecular charge transfer from the phenanthroimidazole to the cyanocarbazole. It also defines the role of the cyano chromophore in extending the conjugation of the $\pi$-electrons in 27CN3PI. To understand the effect of a polar environment on the ground state of the dyes, we evaluated the absorption spectra of all the dyes in different polarity solvents (low polar 
cyclohexane to high polar acetonitrile). All the dyes exhibited similar absorption profiles, independent of the polarity of the solvents, suggesting the non-polar nature of the dyes in the ground state (Fig. 2 and Fig. S1, ESI $\dagger$ ). ${ }^{39}$

The emission spectra of the dyes were recorded in dichloromethane solution $\left(1 \times 10^{-6} \mathrm{M}\right)$ and are displayed in Fig. 1 with the relevant data tabulated in Table 1 . In the emission spectra, all the dyes emit light from the deep-blue to the cyan blue regions in solution with a peak maximum ranging from 422 to $470 \mathrm{~nm}$ depending on the extent of conjugation between the donor and the acceptor units. It is observed that the parent dyes 27PI and 27PHPI displayed a structured emission with two distinguishable vibronic peaks, suggesting the rigidity of the molecules in the excited state. Meanwhile, the substitution of the cyano chromophore at the 3 and/or 6 positions of the carbazole in the 27PI36CN, 27PHPI3CN and 27PHPI36CN dyes leads to the red-shifted emission spectra compared with their parent compounds (27PI and 27PHPI). This is attributed to the greater structural reorientation of the dyes in the excited state, which is further supported by the larger Stokes shift values observed for the cyano-substituted dyes. On the other hand, the derivative 27CN3PI that contains the cyano groups at the $\mathrm{C} 2$ and $\mathrm{C} 7$ positions of the carbazole exhibits the most red-shifted emission peak at $470 \mathrm{~nm}$ among the dyes, which suggests the significant role of changing the position of the substituents in controlling the emission energies. When compared with the known compound 2-(9-hexyl-9H-carbazol-3-yl)-1-phenyl-1 $H$ phenanthro[9,10- $d$ ]imidazole $(\mathbf{H 1}),{ }^{38}$ the emission of 27CN3PI is red-shifted by $65 \mathrm{~nm}$. This is attributable to the intramolecular charge transfer in the excited state from the mild electron-donating phenanthroimidazole group to the electronwithdrawing cyano group on the carbazole core. This observation confirms the role of the cyano chromophore in developing the dipolar character in the dyes.

The solvent polarity effect on the excited state of the dyes is understood via the emission solvatochromism (Fig. 2 and Fig. S2, ESI $\dagger$ ). The parent dyes 27PI and 27PHPI showed a less significant change in the emission spectra on increasing the solvent polarity from low polar cyclohexane to high polar acetonitrile and displayed the same vibronic features in all the solvents. This indicates the absence of ICT transition in the excited state of these dyes and the resulting emission is obtained from the locally excited state of the molecules. However, the incorporation of the cyano unit changes the emission pattern in different polarity solvents. The dyes 27PHPI3CN and 27PHPI36CN displayed a positive response to the emission solvatochromism spectra with the vibronic structured emissive spectra in low polarity solvents originating from the locally excited (LE) state of the dyes converted to broad featureless emission spectra in more polar solvents. This indicates the presence of the charge-transfer (CT) excited state (Table ST1, $\mathrm{ESI} \dagger)$. Hence, it suggests a significant role of the cyano chromophoric unit in the fine tuning of contribution of the LE and CT excited states when compared with their parent compound 27PHPI, which is emitting mainly through the LE component. Interestingly, the change in the spectral shift observed for the dye

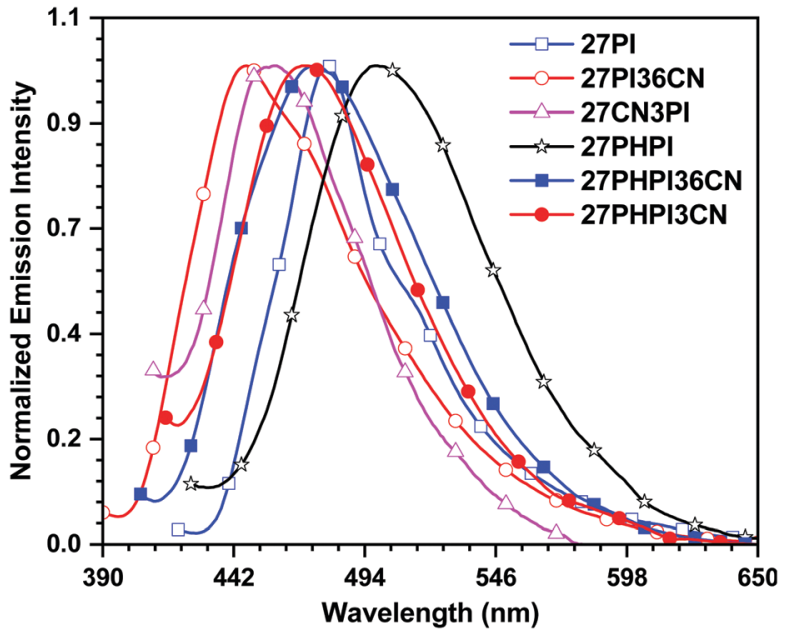

Fig. 3 Photoluminescence spectra of the dyes in thin films prepared using the drop-casting method.

27PHPI36CN is larger than 27PHPI3CN, attributable to a greater dipolar relaxation of the former dye in the excited state. Similarly, the substitution of cyano units at the C3 and C6 positions of the carbazole in the dye 27PI36CN showed a similar spectral change under the influence of solvent polarity with a smaller spectral shift $(20 \mathrm{~nm})$. However, the 27CN3PI dye featuring cyano substitution at the $\mathrm{C} 2$ and $\mathrm{C} 7$ positions offers a more significant spectral shift $(42 \mathrm{~nm})$, indicating the greater stabilization of the excited state in the polar environment to induce photo-excited charge transfer in the molecule.

To further analyze the solvatochromism data, a correlation between the orientation polarizability and the Stokes shift was plotted as per the Lippert-Mataga model and is shown in Fig. 2e. It is observed that the parent dyes 27PI and 27PHPI exhibited a small slope in the LM plots, which indicates that they possess LE character with a smaller contribution of CT. However, the cyano-substituted dyes 27PHPI3CN and 27PHPI36CN possess a larger slope with good correlation between the solvent polarity and the Stokes shift, suggesting a significant contribution from the dominant CT component in the excited state. However, in the dye lacking the phenyl spacer between the carbazole and phenanthroimidazole units (27PI36CN), the data are divided into two separate fitted lines. A smaller slope appears in the lower polarity solvents witnessing the structured emission from the locally excited (LE) state of different chromophores attached to the central carbazole. On the other hand, the CT state emission dominates in the higher polarity solvents with a larger slope indicating the stabilization of the excited state in the polar environment. Meanwhile, the dye 27CN3PI showed a complete CT-dominated excited state with a large dipole moment. This hybridization of two different excited states helps in improving the electroluminescence properties of the dyes. ${ }^{40}$

The solid-state emission of the dyes (Fig. 3 and Table 1) was recorded on thin films obtained using the drop-casting method. All the dyes except 27CN3PI exhibited a red-shifted 
emission compared with their solution spectra (in DCM), attributed to the formation of aggregates in the solid-state. Interestingly, a blue shift of $11 \mathrm{~nm}$ was observed in the dye 27CN3PI, which suggests the twisted intramolecular charge transfer (TICT) state in polar dichloromethane solution and the involvement of the locally excited state in the aggregated state by restricting the intramolecular rotation. ${ }^{41,42}$ The absolute photoluminescence quantum yield (PLQY) was measured in solution and in the solid state using a calibrated integrated sphere method (Table 1). In the DCM solution, all the blue-emitting dyes exhibited a quantum yield higher than 0.80. The PLQY values of the cyano-substituted dyes 27PHPI3CN and 27PHPI36CN were slightly lower than their parent dye 27PHPI, again confirming the intramolecular charge transfer, which facilitates non-radiative transitions. However, the PLQY values of the dyes 27PI36CN and 27CN3PI were estimated to be the highest among all the dyes.

\section{Thermal properties}

The thermal stability of the dyes was estimated using thermogravimetric analysis (TGA) and differential scanning calorimetry (DSC) in the presence of an inert $\left(\mathrm{N}_{2}\right)$ atmosphere with a heating rate of $10{ }^{\circ} \mathrm{C} \mathrm{min}^{-1}$. The thermograms are displayed in Fig. 4 with the thermal decomposition temperature $T_{10 \mathrm{~d}}$ (onset $T_{\mathrm{d}}$ corresponding to $10 \%$ weight loss) and the glass transition temperature presented in Table 1 . As depicted in the TGA spectra, all the dyes exhibited excellent thermal stability with the $T_{10 d}$ values ranging between 435 and $548{ }^{\circ} \mathrm{C}$. The dyes 27PHPI, 27PHPI3CN and 27PHPI36CN exhibited a superior thermal stability over their congeners where carbazole and phenanthroimidazole are not separated by the additional phenyl group. However, the dye 27CN3PI showed a lower thermal decomposition temperature than the other dyes, which is attributable to the lower number of phenanthroimidazole units. However, it is interesting to compare the thermal stability of 27CN3PI with the reported dye 2-(9-hexyl-9H-carbazol-3-yl)-1phenyl- $1 H$-phenanthro $[9,10-d]$ imidazole $(\mathbf{H 1})^{38}$ where no cyano chromophores are available at the $\mathrm{C} 2$ and $\mathrm{C} 7$ positions of the carbazole core. The cyano-decorated dye exhibits a higher $T_{\mathrm{d}}$ value than its known derivative $\mathbf{H 1}$ and suggests a key role of the cyano chromophores in improving the thermal stability of the molecules. The superior thermal robustness of the cyanodecorated dyes over their parent dyes is attributed to the functionalization at the C3 and/or the C6 position of the carbazole core, leading to an enhanced molecular dipole. ${ }^{43}$ The higher robustness of the dyes suggests excellent thermal stability, which is essential for organic electronic applications.

The DSC curves reveal high glass-transition temperatures $\left(T_{\mathrm{g}}\right)$ in the range of $150-155{ }^{\circ} \mathrm{C}$, indicating the high morphological stability of the compounds. These high $T_{\mathrm{g}}$ values are attributable to the rigid and bulky nature of the carbazole and phenanthroimidazole groups, respectively. High thermal stability guarantees stable and homogeneous film formation and therefore alleviates the potential applicability of these materials in solutionprocessed OLED devices.

\section{Electrochemical properties}

The electrochemical stability of the dyes was investigated via cyclic voltammetry and differential pulse voltammetry analysis in dichloromethane solution $\left(1 \times 10^{-4} \mathrm{M}\right)$ (Fig. S3, ESI $\left.\dagger\right)$. The HOMO energy levels of the dyes were calculated with respect to the ionization potential of ferrocene (HOMO $=-\left(4.8+E_{\mathrm{ox}}\right)$, where $E_{\mathrm{ox}}$ is the first oxidation potential) (Table 1). The band gaps of the dyes were obtained from the optical edges of the absorption and emission spectra, which were further utilized to calculate the LUMO energy levels (LUMO $=\mathrm{HOMO}+E_{0-0}$ ). An irreversible oxidation curve was displayed by all the dyes, which is attributed to the greater reorganization energy during the oxidation of the rigid framework. ${ }^{44}$ The higher oxidation ability of the dyes 27PI and 27PHPI over the cyano-substituted derivatives arises due to the absence of electron-withdrawing cyano groups in the former cases. However, it is also observed that the oxidation potential of the dyes increases upon increasing the number of cyano groups as the $E_{\mathrm{Ox}}$ follows the trend 27PHPI $<27$ PHPI3CN

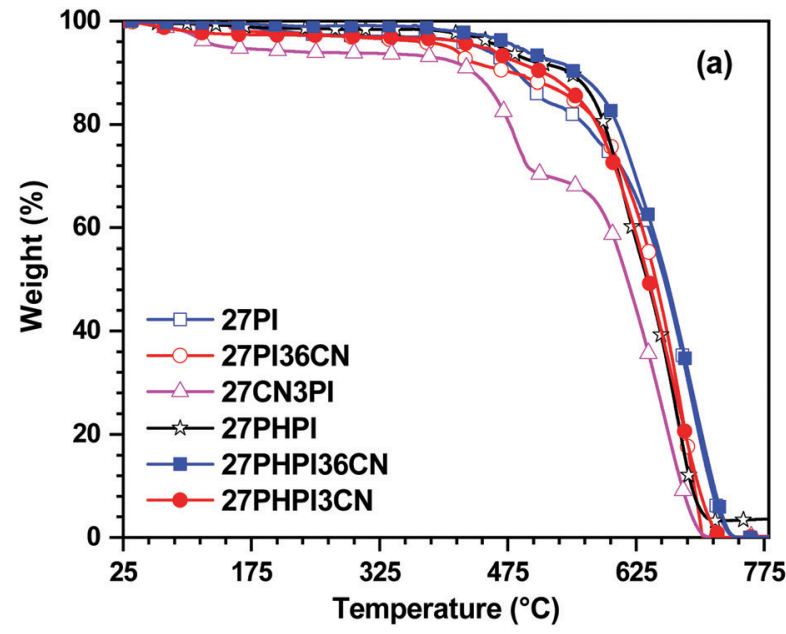

Fig. 4 (a) Thermograms and (b) DSC curves of the dyes.

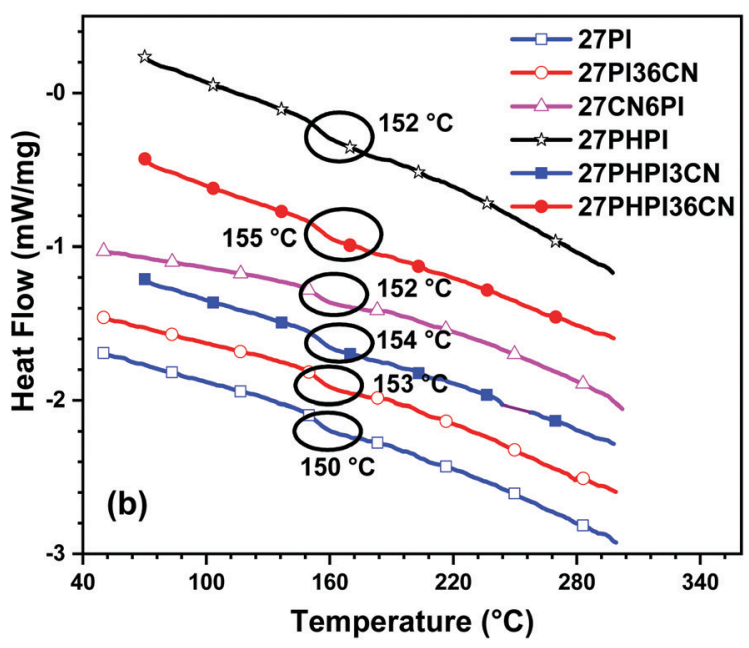


27PI

.

\begin{abstract}
$<$ 27PHPI36CN and 27PI $<$ 27PI36CN. This illustrates the key role of the cyano groups in depleting the electron richness of the dyes by the removal of electron density.
\end{abstract}

The highest occupied molecular orbital (HOMO) was obtained in the range of -5.38 to $-5.93 \mathrm{eV}$, whereas the lowest unoccupied molecular orbital (LUMO) falls in the range of -2.34 to $2.91 \mathrm{eV}$. The dye 27CN3PI exhibits the lowest-lying LUMO in the series, which is attributed to the strong $\pi$-accepting ability of the cyano groups at the 2 and 7 positions of the central carbazole. The increasing order of LUMO energy levels is as follows: 27PI $<2$ 27PHPI $<$ 27PHPI3CN $<27$ PI36CN $<$ 27PHPI36CN $<$ 27CN3PI. Thus, this confirms that the cyano-substituted dyes allow better stabilization of the LUMO energy levels when compared with those dyes that are lacking it, and the effect is directly proportional to the number of cyano units.

\section{Theoretical investigation}

To understand the electronic and geometric properties of the dyes at the molecular level, density functional theory (DFT) calculations were performed using the B3LYP functional and the $6-31 \mathrm{G}(\mathrm{d}, \mathrm{p})$ basis set implemented in Gaussian $16 .{ }^{45}$ The optimized geometry of the dyes with different dihedral angles is shown in Fig. S4 (ESI $\dagger$ ). The increased dihedral angle in the dye 27PHPI $\left(\sim 37^{\circ}\right)$ as compared with 27PI $\left(\sim 29^{\circ}\right)$ is attributed to the twisted nature of the additional phenyl group between the carbazole and the PI unit in the former dye. The cyano substitution at the $\mathrm{C} 3$ and/or the $\mathrm{C} 6$ position of the carbazole in 27PI36CN $\left(\sim 60^{\circ}\right), 27$ PHPI3CN and 27PHPI36CN $\left(\sim 47^{\circ}\right)$ leads to larger dihedral angles when compared with their parent molecules (27PI and 27PHPI). This is attributed to the increased steric hindrance between the cyano group and the bulky phenanthroimidazole or phenylphenanthroimidazole unit, resulting in twisting of the PI chromophore. However, the twisting between the appended chromophores is less in 27PHPI3CN or 27PHPI36CN when compared with 27PI36CN, which indicates the steric relief offered by the phenyl spacer between the carbazole and the PI unit.

The spatial electronic distribution in the frontier molecular orbitals, i.e., the HOMO and LUMO, of the dyes in the ground state is represented in Fig. 5. The linearly substituted phenanthroimidazole derivatives (27PI and 27PHPI) acquired the

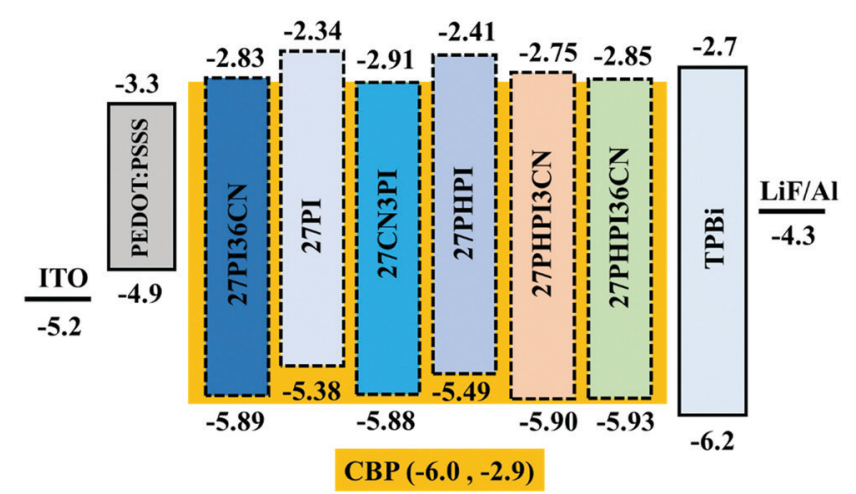

Fig. 6 Energy-level diagrams of the materials used in the fabrication of the OLED devices. 
dispersion of frontier molecular orbitals (HOMO and LUMO) over the entire molecule. Meanwhile, the well-separable HOMO and LUMO of the cyano-substituted derivatives indicate the possibility of charge transfer. The HOMO of the dyes 27PI36CN, 27PHPI3CN, 27PHPI36CN and 27CN3PI is mainly located over the phenanthroimidazole or its C2-linked phenylphenanthroimidazole moieties and slightly extended to the central carbazole, whereas the LUMO is dispersed over the cyanocarbazole fragment. This clearly demonstrates the shifting of the electronic density from phenanthroimidazole to the electron-deficient
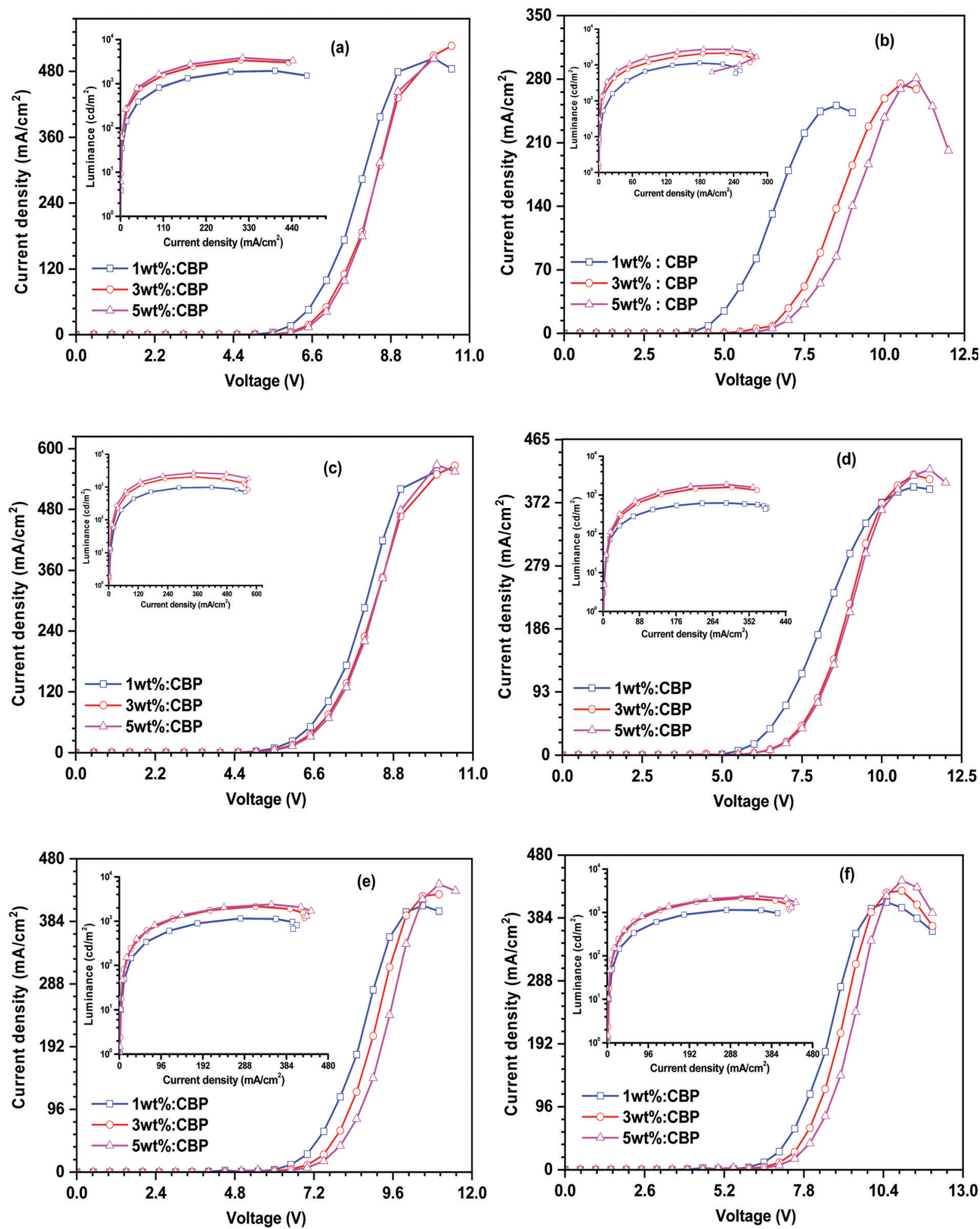

Fig. 7 Current density-voltage-luminance relationship of the dyes (a) 27PI36CN, (b) 27CN3PI, (c) 27PI, (d) 27PHPI, (e) 27PHPI3CN and (f) 27PHPI36CN. 
Table 2 EL characteristics of the dyes

\begin{tabular}{|c|c|c|c|c|c|c|}
\hline Dye & $\begin{array}{l}\text { Concentraton } \\
(\mathrm{wt} \%)^{a}\end{array}$ & $\begin{array}{l}\mathrm{PE}_{100} / \mathrm{CE}_{100} / \mathrm{EQE}_{100} \\
\left(\operatorname{lm~W} \mathrm{W}^{-1} / \mathrm{cd} \mathrm{A}^{-1} / \%\right)\end{array}$ & $\begin{array}{l}\mathrm{PE}_{1000} / \mathrm{CE}_{1000} / \mathrm{EQE}_{1000} \\
\left(\operatorname{lm~W} \mathrm{W}^{-1} / \mathrm{cd} \mathrm{A}^{-1} / \%\right)\end{array}$ & $\operatorname{CIE}^{b}$ & $\begin{array}{l}\text { Max. luminescence } \\
\left(\mathrm{cd} \mathrm{m}^{-2}\right)\end{array}$ & EL max. (nm) \\
\hline \multirow[t]{2}{*}{ 27CN3PI } & 1 & $0.4 / 0.6 / 4.1$ & $0.5 / 0.7 / 4.3$ & $(0.16,0.05) /(0.18,0.11)$ & 1129 & 392 \\
\hline & 3 & $0.9 / 1.8 / 5.7$ & $0.9 / 1.8 / 5.7$ & $(0.16,0.06) /(0.16,0.08)$ & 2124 & 420 \\
\hline \multirow[t]{3}{*}{ 27PI36CN } & 1 & $0.5 / 0.9 / 2.3$ & $0.4 / 0.8 / 1.8$ & $(0.16,0.07) /(0.16,0.08)$ & 1953 & 388 \\
\hline & 3 & $0.9 / 1.6 / 2.3$ & $0.7 / 1.5 / 2.4$ & $(0.15,0.08) /(0.15,0.08)$ & 3375 & 428 \\
\hline & 5 & $1.0 / 2.0 / 2.4$ & $0.8 / 1.8 / 2.4$ & $(0.16,0.10) /(0.16,0.10)$ & 3875 & 432 \\
\hline & 5 & $0.3 / 0.6 / 0.5$ & $0.5 / 1.1 / 1$ & $(0.16,0.14) /(0.16,0.13)$ & 2736 & 432 \\
\hline \multirow[t]{3}{*}{ 27PHPI } & 1 & $0.2 / 0.4 / 0.7$ & $-1-1-$ & $(0.16,0.09) /-$ & 622 & 420 \\
\hline & 3 & $0.2 / 0.5 / 0.7$ & $0.3 / 0.7 / 1.0$ & $(0.16,0.09) /(0.16,0.09)$ & 1588 & 428 \\
\hline & 5 & $0.3 / 0.6 / 0.8$ & $0.3 / 0.9 / 1.2$ & $(0.16,0.09) /(0.16,0.09)$ & 1856 & 428 \\
\hline \multirow[t]{3}{*}{ 27PHPI3CN } & 1 & $0.2 / 0.5 / 0.9$ & $0.2 / 0.5 / 0.9$ & $(0.16,0.08) /-$ & 1148 & 420 \\
\hline & 3 & $0.3 / 0.8 / 1.1$ & $0.3 / 0.9 / 1.4$ & $(0.16,0.09) /(0.16,0.09)$ & 2149 & 424 \\
\hline & 5 & $0.3 / 0.8 / 1.0$ & $0.4 / 1.0 / 1.3$ & $(0.16,0.09) /(0.16,0.10)$ & 2379 & 428 \\
\hline
\end{tabular}

cyanocarbazole upon excitation. The computed HOMO and LUMO energy levels, orbital contribution, band gap and vertical excitation transitions with their oscillator strength are given in Table ST2 (ESI $\dagger$ ). The calculated physiochemical parameters of the dyes are comparable to those obtained from experimental studies.

\section{Electroluminescence characteristics}

Encouraged by the promising photophysical characteristics, good thermal stability and good electrochemical stability of the dyes, we attempted to utilize these dyes as fluorescent dopant emitters in a multilayer solution-processed OLED device. To eliminate the risk of concentration quenching in the device, and thus improving the efficacy of electroluminescence, the materials were used at different doping concentrations ranging from $1 \mathrm{wt} \%$ to $5 \mathrm{wt} \%$ with a wide-energy gap host material, namely 4,4'-bis(9H-carbazol-9-yl)biphenyl (CBP). The optimized OLED device configuration is ITO/PEDOT:PSS/CBP + (27PI or 27PI36CN or 27CN3PI or 27PHPI or 27PHPI3CN or 27PHPI36CN)/TPBi/LiF:Al. Here, PDOT:PSS (poly(3,4-ethylenedioxythiophene)poly(styrenesulfonate) and TPBi (1,3,5-tris( $N$ phenylbenzimidazol-2-yl)benzene) served as the device hole- and electron-transporting materials, respectively. Meanwhile, an indium tin oxide (ITO)-coated glass substrate and $\mathrm{Al}$ (aluminum) fulfilled the role of anode and cathode, respectively, and LiF helps in facilitating the injection of electrons entering from the cathode side. The hole-only and electron-only devices were also fabricated with the configuration of ITO/PEDOT:PSS/TAPC/ Emitters/TAPC/LiF/Al and ITO/TPBi/Emitters/TPBi/LiF/Al, respectively. The corresponding current density $v s$. voltage spectra are represented in Fig. S5 (ESI $\dagger$ ). The single-carrier devices demonstrate the bipolar charge-transporting properties of the designed fluorophores materials. Fig. 6 depicts the energy level alignments of various layers of the device along with the electrodes.
The current density-voltage-luminance $(J-V-L)$ plot of the OLED device is shown in Fig. 7 and the respective data are listed in Table 2. The higher current densities of the cyanosubstituted dyes over their parent congeners are attributed to the facile transportation of charge carriers originating from the balanced charge transport due to the cyano substitution. This is probably due to the low-lying LUMO energy levels of the cyanosubstituted-based devices enabling the balanced injection of holes and electrons to generate excitons in the emissive layer (EML). Also, they displayed better luminance characteristics when compared with dyes lacking the cyano chromophores, which further confirms the efficient charge recombination in the EML.

The electroluminescence spectra of the devices based on the synthesized emitters are displayed in Fig. 8 and the relevant parameters are shown in Table 2. The EL spectra of the dyes exhibit deep-blue emission with maxima ranging between $420 \mathrm{~nm}$ and $436 \mathrm{~nm}$. They are in close proximity with the photoluminescence spectrum of the dyes measured in the toluene solution. This suggests the favorable energy transfer from the excitons generated by CBP and captured effectively by the emitters. However, the 27PI36CN- and 27CN3PI-based devices displayed the emission originating from the host molecule at the $1 \mathrm{wt} \%$ dopant concentration, indicating insufficient energy transfer from the host to the dopant emitter at the lower doping concentration. Moreover, a red shift of EL emission for the 27CN3PI-based device was observed at higher dopant concentrations ( $1 \mathrm{wt} \%$ to $3 \mathrm{wt} \%$ to $5 \mathrm{wt} \%$ ), which is attributable to aggregation. The OLED device fabricated using the cyano-substituted dyes displayed a higher current efficiency and power efficiency along with enhanced luminance when compared with the non-cyano-based doped devices. This is attributed to well-balanced charge transport occurring in the device, resulting in the facile recombination of holes and electrons in the emissive layer. Overall, the device constructed using 27CN3PI as the dopant emitter performed best, which 

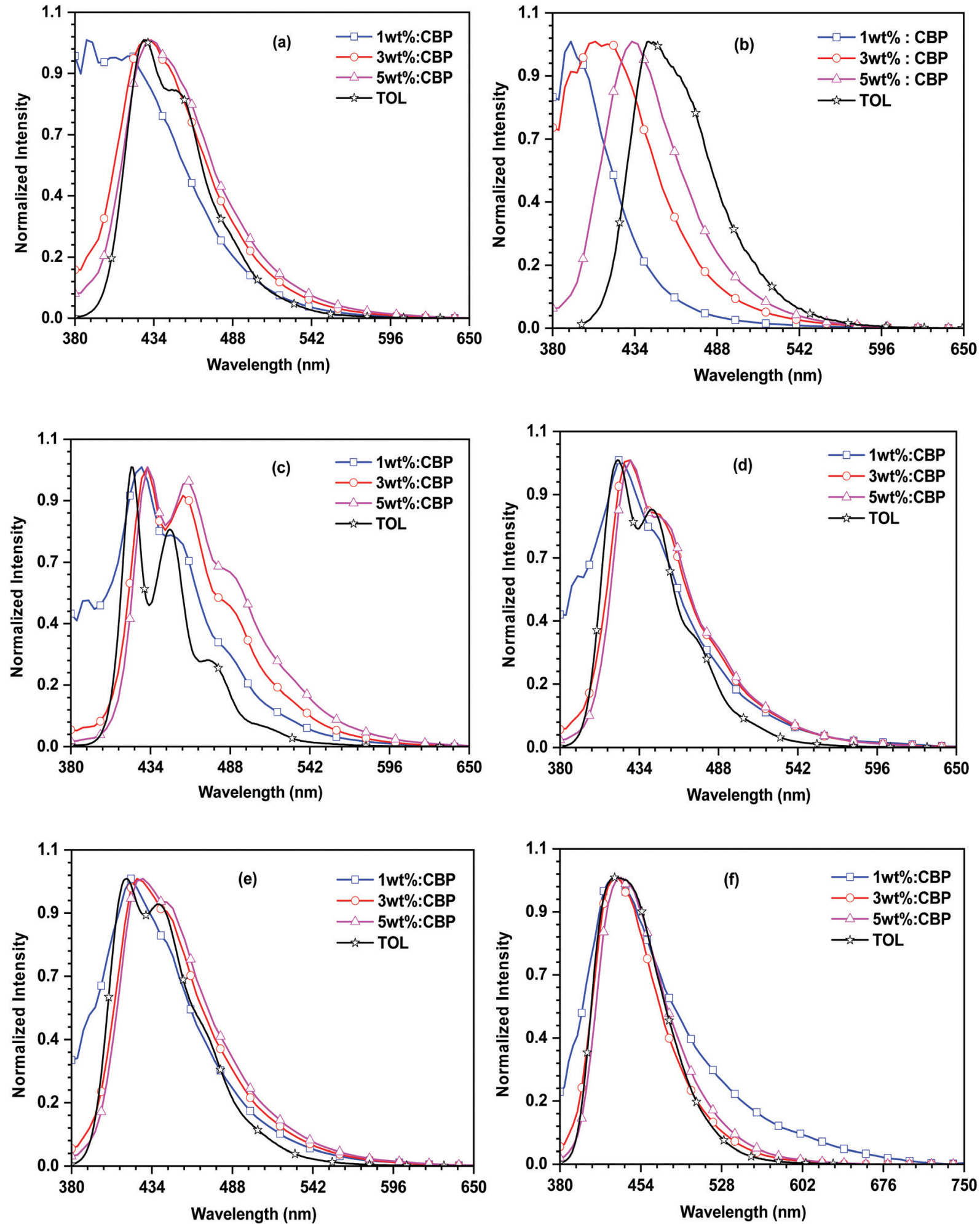

Fig. 8 EL and PL spectral comparison of the dyes (a) 27PI36CN, (b) 27CN3PI, (c) 27PI, (d) 27PHPI, (e) 27PHPI3CN and (f) 27PHPI36CN.

can be explained by its low-lying LUMO enabling effective electron injection from the adjacent ETL. The maximum EQE obtained from the 27CN3PI-based device is $5.7 \%$ at the $3 \mathrm{wt} \%$ doping concentration and with a maximum luminance of $2124 \mathrm{~cd} \mathrm{~m}^{-2}$, a current efficiency of $1.8 \mathrm{~cd} \mathrm{~A}^{-1}$ and a power efficiency of $0.9 \mathrm{~lm} \mathrm{~W}^{-1}$. The molecules 27PI, 27PHPI, 27PI36CN, 27PHPI3CN, 27PHPI36CN, and 27CN3PI display EUE values of 9.8, 10.3, 19.0, 11.9, 16.1, and 83.8\%, respectively. Accordingly, the 27CN3PI-based device exhibit a high EQE of $5.7 \%$ due to the higher EUE. 


\section{Conclusions}

In conclusion, we have successfully synthesized efficient deep-blue emitters based on carbazole-phenanthroimidazole bipolar materials by fine tuning the position and number of cyano groups on the carbazole core. The structure-property relationships of the dyes have been thoroughly investigated via physiochemical measurements. The emission spectra revealed a blue to cyan color depending upon the position of the cyano units. The dyes exhibited a red shift by switching the cyano acceptor from the C3 and C6 positions of the carbazole to the $\mathrm{C} 2$ and $\mathrm{C} 7$ positions of the carbazole, which attributed to increased charge transfer in the latter dyes. The absorption solvatochromism studies revealed the ground state of the dyes to be less sensitive to the solvent polarity, whereas the dyes except for 27PI and 27PHPI showed positive emission solvatochromism, suggesting the increase of the charge-transfer component upon increasing the polarity of the medium. Moreover, the role of a number of phenanthroimidazole and cyano chromophoric units has been deduced via thermal analysis, where the thermal stability increases upon increasing the PI and cyano substituents. The electrochemical properties also indicate the crucial role of cyano substitution in lowering the LUMO energy levels and hence decreasing the band gap of the molecules. Simple modulation of the emissive state energy has been investigated via the cyano unit functionalization, leading to a better electroluminescence performance and a maximum EQE reaching nearly $6 \%$ with good current and power efficiency in the CBP-doped OLED device. We believe this strategy of cyano incorporation and modulation of the charge-transfer state to be a practical approach for the design of efficient and low-cost materials that are applicable for OLED devices.

\section{Conflicts of interest}

There are no conflicts to declare.

\section{Acknowledgements}

K. R. J. T. is thankful to the Science and Engineering Research Board (SERB), New Delhi (CRG/2018/003729), and the Council of Scientific and Industrial Research (CSIR), New Delhi (02(0371)/19/EMR-II), for financial support. A. S. is grateful to the University Grant Commission (UGC), Government of India, for a research fellowship.

\section{References}

1 K. Wang, S. Wang, J. Wei, S. Chen, D. Liu, Y. Liu and Y. Wang, J. Mater. Chem. C, 2014, 2, 6817-6826.

2 S. K. Jeon, H.-J. Park and J. Y. Lee, J. Mater. Chem. C, 2018, 6, 6778-6783.

3 Z. Xu, B. Z. Tang, Y. Wang and D. Ma, J. Mater. Chem. C, 2020, 8, 2614-2642.

4 Y. Liu, T. Shan, L. Yao, Q. Bai, Y. Guo, J. Li, X. Han, W. Li, Z. Wang, B. Yang, P. Lu and Y. Ma, Org. Lett., 2015, 17, 6138-6141.
5 A. Pathak, K. R. J. Thomas, M. Singh and J.-H. Jou, J. Org. Chem., 2017, 82, 11512-11523.

6 M. S. Subeesh, K. Shanmugasundaram, C. D. Sunesh, R. K. Chitumalla, J. Jang and Y. Choe, J. Phys. Chem. C, 2016, 120, 12207-12217.

7 Y. Zhang, S.-L. Lai, Q.-X. Tong, M.-Y. Chan, T.-W. Ng, Z.-C. Wen, G.-Q. Zhang, S.-T. Lee, H.-L. Kwong and C.-S. Lee, J. Mater. Chem., 2011, 21, 8206-8214.

8 (a) M. S. Subeesh, K. Shanmugasundaram, C. D. Sunesh, Y. S. Won and Y. Choe, J. Mater. Chem. C, 2015, 3, 4683-4687; (b) W.-C. Chen, Q.-X. Tong and C.-S. Lee, Sci. Adv. Mater., 2015, 7, 2193-2205.

9 Y. Yuan, D. Li, X. Zhang, X. Zhao, Y. Liu, J. Zhang and Y. Wang, New J. Chem., 2011, 35, 1534-1540.

10 (a) W.-C. Chen, C.-S. Lee and Q.-X. Tong, J. Mater. Chem. C, 2015, 3, 10957-10963; (b) R. Z. J. Shao, X. Zhao, X. He, Z. Zhang and R. Zhai, Asian J. Chem., 2018, 30, 2424-2430.

11 (a) S. Zhang, W. Li, L. Yao, Y. Pan, F. Shen, R. Xiao, B. Yang and Y. Ma, Chem. Commun., 2013, 49, 11302-11304; (b) X. Chen, H. Zhang, H.-J. Tan, L. Yang, P. Qin, X.-H. Zheng, S.-S. Tang, Y. Liu and Q.-X. Tong, Chem. Eur. J., 2021, 7, 7275-7282.

12 W.-C. Chen, Y. Yuan, G.-F. Wu, H.-X. Wei, J. Ye, M. Chen, F. Lu, Q.-X. Tong, F.-L. Wong and C.-S. Lee, Org. Electron., 2015, 17, 159-166.

13 (a) J.-J. Zhu, Y. Chen, Y.-H. Xiao, X. Lian, G.-X. Yang, S.-S. Tang, D. Ma, Y. Wang and Q.-X. Tong, J. Mater. Chem. C, 2020, 8, 2975-2984; (b) G.-X. Yang, Y. Chen, J.-J. Zhu, J.-Y. Song, S.S. Tang, D. Ma and Q.-X. Tong, Dyes Pigm., 2021, 187, 109088. 14 (a) Y. Yu, Y. Fan, C. Wang, Y. Wei, Q. Liao, Q. Li and Z. Li, J. Mater. Chem. C, 2019, 7, 13759-13763; (b) J.-J. Zhu, W.-C. Chen, Y. Yuan, D. Luo, Z.-L. Zhu, X. Chen, J.-X. Chen, C.-S. Lee and Q.-X. Tong, Dyes Pigm., 2020, 173, 107982.

15 Z. Huang, S. Xiang, Q. Zhang, X. Lv, S. Ye, R. Guo and L. Wang, J. Mater. Chem. C, 2018, 6, 2379-2386.

16 Z. Wang, X. Li, K. Xue, H. Li, X. Zhang, Y. Liu, Z. Yu, P. Lu and P. Chen, J. Mater. Chem. C, 2016, 4, 1886-1894.

17 X. Li, Y. Lv, S. Chang, H. Liu, W. Mo, H. Ma, C. Zhou, S. Zhang and B. Yang, Anal. Chem., 2019, 91, 10927-10931.

18 Z. Wang, X. Li, W. Zhang, S. Zhang, H. Li, Z. Yu, Y. Chen, P. Lu and P. Chen, Phys. Chem. Chem. Phys., 2015, 17, 31894-31901.

19 J. Tagare, D. K. Dubey, J.-H. Jou and S. Vaidyanathan, ChemistrySelect, 2019, 4, 6458-6468.

20 A. Kundu, S. Karthikeyan, Y. Sagara, D. Moon and S. P. Anthony, ACS Omega, 2019, 4, 5147-5154.

21 S.-T. Zhang, X. Bai, X. Li, Q. Bai, M. Wang, H. Liu, P. Lu, S.-J. Su and B. Yang, Org. Electron., 2019, 75, 105404.

22 M. Chen, Y. Yuan, J. Zheng, W.-C. Chen, L.-J. Shi, Z.-L. Zhu, F. Lu, Q.-X. Tong, Q.-D. Yang, J. Ye, M.-Y. Chan and C.-S. Lee, Adv. Opt. Mater., 2015, 3, 1215-1219.

23 R. K. Konidena, K. H. Lee and J. Y. Lee, J. Mater. Chem. C, 2019, 7, 13912-13919.

24 Y. Gao, S. Zhang, Y. Pan, L. Yao, H. Liu, Y. Guo, Q. Gu, B. Yang and Y. Ma, Phys. Chem. Chem. Phys., 2016, 18, 24176-24184. 
25 M. K. Nayak, J. Photochem. Photobiol., A, 2012, 241, 26-37.

26 J. Jayabharathi, J. Anudeebhana, V. Thanikachalam and S. Sivaraj, RSC Adv., 2020, 10, 8866-8879.

27 Z. Li, C. Li, Y. Xu, N. Xie, X. Jiao and Y. Wang, J. Phys. Chem. Lett., 2019, 10, 842-847.

28 L. Zheng and R. Hua, J. Org. Chem., 2014, 79, 3930-3936.

29 J. Tagare, H. Ulla, M. N. Satyanarayan and S. Vaidyanathan, J. Photochem. Photobiol., A, 2018, 353, 53-64.

30 T. Jadhav, J. M. Choi, B. Dhokale, S. M. Mobin, J. Y. Lee and R. Misra, J. Phys. Chem. C, 2016, 120, 18487-18495.

31 J.-H. Jou, J. L. Li, S. Sahoo, D. K. Dubey, R. A. Kumar Yadav, V. Joseph, K. R. J. Thomas, C. W. Wang, J. Jayakumar and C. H. Cheng, J. Phys. Chem. C, 2018, 122, 24295-24303.

32 A. Sharma, D. Saklani, K. R. J. Thomas, Shahnawaz, S. S. Swayamprabha and J.-H. Jou, Org. Electron., 2020, 86, 105864.

33 (a) R. K. Konidena, K. R. J. Thomas, A. Pathak, D. K. Dubey, S. Sahoo and J.-H. Jou, ACS Appl. Mater. Interfaces, 2018, 10, 24013-24027; (b) J. Peng, K. Ye, G. Zhang, Y. Zhan, J. Jia, P. Xue and R. Lu, Synth. Met., 2014, 193, 94-101; (c) R. Butkute, R. Lygaitis, V. Mimaite, D. Gudeika, D. Volyniuk, G. Sini and J. V. Grazulevicius, Dyes Pigm., 2017, 146, 425-437; (d) A. Sharma, R. Balasaravanan, K. R. J. Thomas, M. Ram, D. K. Dubey, R. A. K. Yadav and J.-H. Jou, Dyes Pigm., 2021, 184, 108830.

34 M.-J. Park, J. Kwak, J. Lee, I. H. Jung, H. Kong, C. Lee, D.-H. Hwang and H.-K. Shim, Macromolecules, 2010, 43, 1379-1386.

35 D. Karthik, K. R. J. Thomas, J.-H. Jou and Y. L. Chen, Dyes Pigm., 2016, 133, 132-142.

36 D. Tavgeniene, G. Krucaite, U. Baranauskyte, J.-Z. Wu, H.-Y. Su, C.-W. Huang, C.-H. Chang and S. Grigalevicius, Dyes Pigm., 2017, 137, 615-621.

37 H. Huang, Y. Wang, S. Zhuang, X. Yang, L. Wang and C. Yang, J. Phys. Chem. C, 2012, 116, 19458-19466.
38 Z. Gao, Z. Wang, T. Shan, Y. Liu, F. Shen, Y. Pan, H. Zhang, X. He, P. Lu, B. Yang and Y. Ma, Org. Electron., 2014, 15, 2667-2676.

39 V. Joseph, K. R. J. Thomas, S. Sahoo, M. Singh and J.-H. Jou, Dyes Pigm., 2018, 158, 295-305.

40 S. Zhang, L. Yao, Q. Peng, W. Li, Y. Pan, R. Xiao, Y. Gao, C. Gu, Z. Wang, P. Lu, F. Li, S. Su, B. Yang and Y. Ma, Adv. Funct. Mater., 2015, 25, 1755-1762.

41 Z.-M. Wang, X.-H. Song, Z. Gao, D.-W. Yu, X.-J. Zhang, P. Lu, F.-Z. Shen and Y.-G. Ma, RSC Adv., 2012, 2, 9635-9642.

42 B. Liu, Y. Yuan, D. He, D.-Y. Huang, C.-Y. Luo, Z.-L. Zhu, F. Lu, Q.-X. Tong and C.-S. Lee, Chem. - Eur. J., 2016, 22, 12130-12137.

43 M.-S. Lin, S.-J. Yang, H.-W. Chang, Y.-H. Huang, Y.-T. Tsai, C.-C. Wu, S.-H. Chou, E. Mondal and K.-T. Wong, J. Mater. Chem., 2012, 22, 16114-16120.

44 V. Joseph, K. R. J. Thomas, S. Sahoo, M. Singh, D. K. Dubey and J.-H. Jou, ACS Omega, 2018, 3, 16477-16488.

45 M. J. Frisch, G. W. Trucks, H. B. Schlegel, G. E. Scuseria, M. A. Robb, J. R. Cheeseman, G. Scalmani, V. Barone, G. A. Petersson, H. Nakatsuji, X. Li, M. Caricato, A. V. Marenich, J. Bloino, B. G. Janesko, R. Gomperts, B. Mennucci, H. P. Hratchian, J. V. Ortiz, A. F. Izmaylov, J. L. Sonnenberg, D. Williams-Young, F. Ding, F. Lipparini, F. Egidi, J. Goings, B. Peng, A. Petrone, T. Henderson, D. Ranasinghe, V. G. Zakrzewski, J. Gao, N. Rega, G. Zheng, W. Liang, M. Hada, M. Ehara, K. Toyota, R. Fukuda, J. Hasegawa, M. Ishida, T. Nakajima, Y. Honda, O. Kitao, H. Nakai, T. Vreven, K. Throssell, J. A. Montgomery Jr., J. E. Peralta, F. Ogliaro, M. J. Bearpark, J. J. Heyd, E. N. Brothers, K. N. Kudin, V. N. Staroverov, T. A. Keith, R. Kobayashi, J. Normand, K. Raghavachari, A. P. Rendell, J. C. Burant, S. S. Iyengar, J. Tomasi, M. Cossi, J. M. Millam, M. Klene, C. Adamo, R. Cammi, J. W. Ochterski, R. L. Martin, K. Morokuma, O. Farkas, J. B. Foresman and D. J. Fox, Gaussian 09, Revision A.02, Gaussian Inc., Wallingford CT, 2009. 